\title{
Condition Monitoring of Back to Back HVDC Transmission System using Artificial Neural Network
}

\author{
Disharika Badgotiya ${ }^{1}$, Dr. Pragya Nema ${ }^{2}$ \\ M. Tech Scholar, Department of Electrical \& Elec. Engineering, Oriental University Indore ${ }^{1}$ \\ Associate Professor, Department of Electrical \& Elec, Engineering, Oriental University Indore 2
}

\begin{abstract}
Fault detection process is much more complex in HVDC systems as many circuits and accessories are involved in this system which is much than HVAC systems. Here an attempt is made to monitor the condition of whole HVDC system. The HVDC system not only involves converter and inverter but have other parts too which are; grid systems, firing circuits, filters, sensing units, protections system and transmission lines. The condition monitoring involve overall present situations of entire system which ultimately ease the operation and maintenance of system and prevent unpredicted breakdowns. The proposed work is a condition monitoring system for back to back HVDC system using artificial neural network.
\end{abstract}

Keywords: Artificial Neural Network, Faults, HVDC System, Training.

\section{INTRODUCTION}

HVDC systems have a long history in electrical engineering. In the early age of electricity, all distribution systems were DC. However, as the electrical grid grew there was an increasing demand for higher voltage and power levels, making HVAC systems the norm . In more recent years however, HVDC systems have seen an increase in popularity, and is a popular choice for several applications. These are mainly bulk power transmission across long distances, and the interconnection of HVAC systems operating at different frequencies from one another, known as asynchronous networks. HVDC is also often preferred over HVAC for use in cables, as this drastically decreases voltage loss. So far all HVDC systems, with a few exceptions, are point to point systems, meaning the power transfer is merely between two converter stations, either connected with cable or overhead line. With recent increase in power demand and production, and especially the increasing renewable share, serious effort has been devoted to examine the feasibility of more complex HVDC systems with several converters interconnected. Such a system is known as a Multi Terminal HVDC (MTDC) system. There are a few in current operations, with the three converter Canadian Quebec-New England connection being amongst the first.

\section{HVDC SYSTEM CONFIGURATION}

\section{- Monopolar System}

In Monopolar systems, each converter station consists of a single converter. The resulting maximum system voltage and power is thus equal to the maximum rating of the converter. Monopolar systems further distinguished as either asymmetrical or symmetrical.

\section{- Bipolar System}

If voltage and power rating is to be increased beyond what is possible for a single converter, two converters can be connected together in a bipolar configuration,. The bipolar configuration is basically two Monopolar systems operating in parallel, at equal voltage levels but with opposite polarity from one another. The bipolar system is similar to the symmetrical monopole, but the extra converter operating in parallel ensures increased redundancy, allowing the system to continue operation at half the rated voltage in case of a fault on either pole. Bipolar systems are grounded at the DC midpoint between the converters to provide a neutral point. The neutral points of each converter can be connected together with metallic return, but during normal operation of both poles the neutral current will be zero.

\section{DIFFERENT GRID TOPOLOGIES}

An HVDC grid can be imagined both as an independent grid, or as an overlay grid alleviating the strain on existing HVAC grids which are close to their maximum operating point.

There are several advantages for choosing HVDC over HVAC for the future expansion of the high voltage power transmission:

Lower number of cables and reduced visual impact

- Enables power exchange between asynchronous networks

- Lower losses over long distances

- Improves performance in parallel HVAC grid 


\section{PROPOSED WORK}

The proposed work is divided in two section first one is problem domain and last one is solution domain. Figure 1.1 shows the configuration of HVDC system which is going to simulate through mat lab enviuorment. Figure no 1.1 shows the algorithm for problem domain and figure no 1.3 shows the algorithm for solution domain

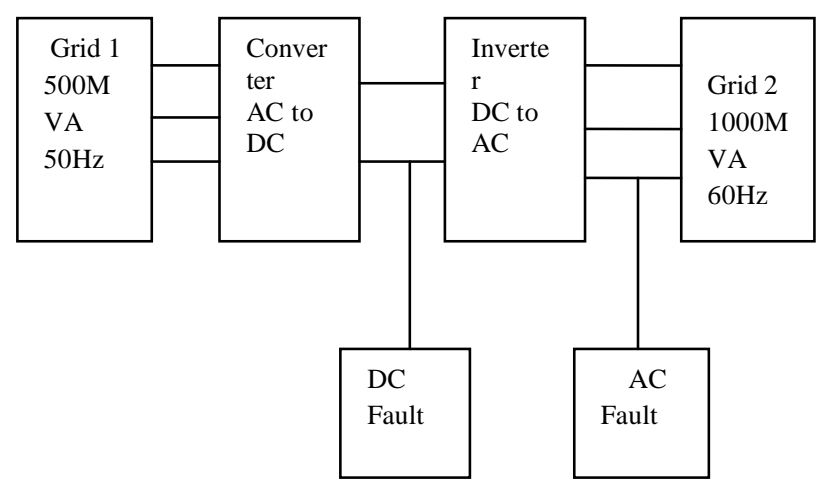

Figure no 1.1 HVDC system

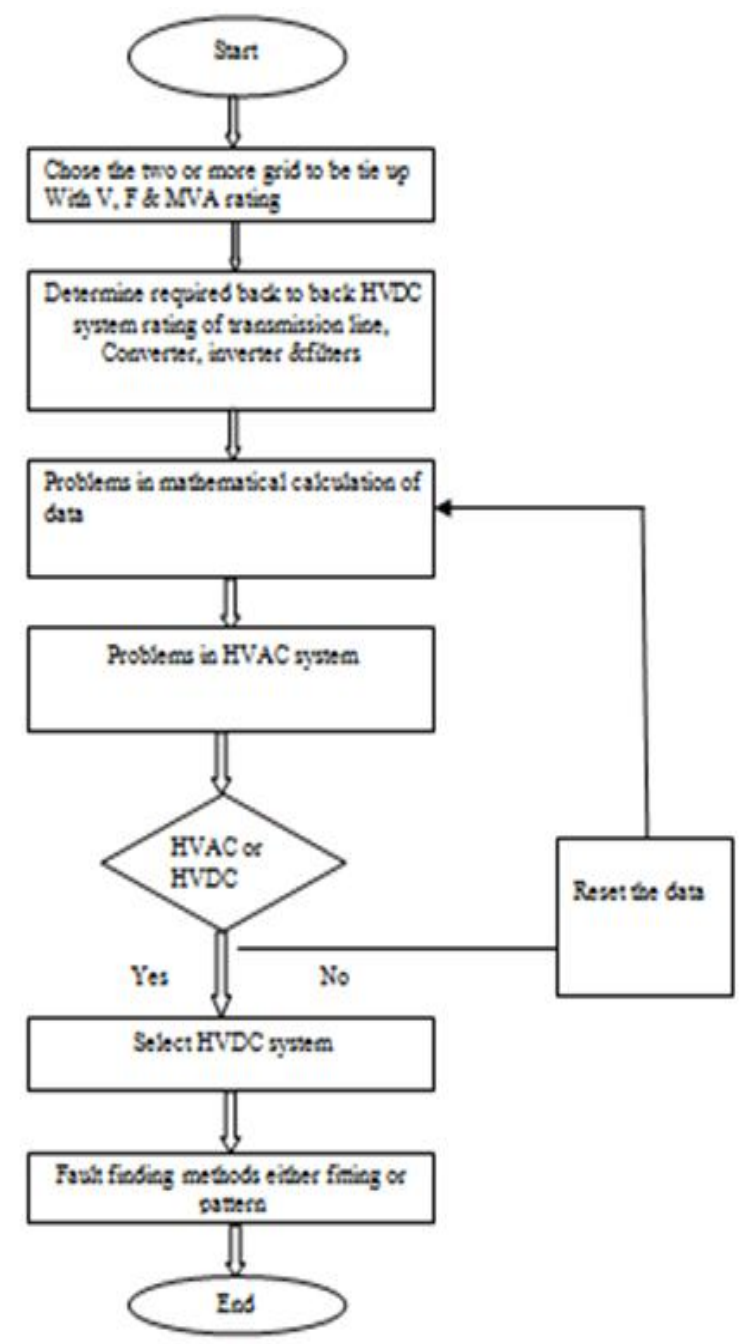

Figure no 1.2Problem Domain Algorithm

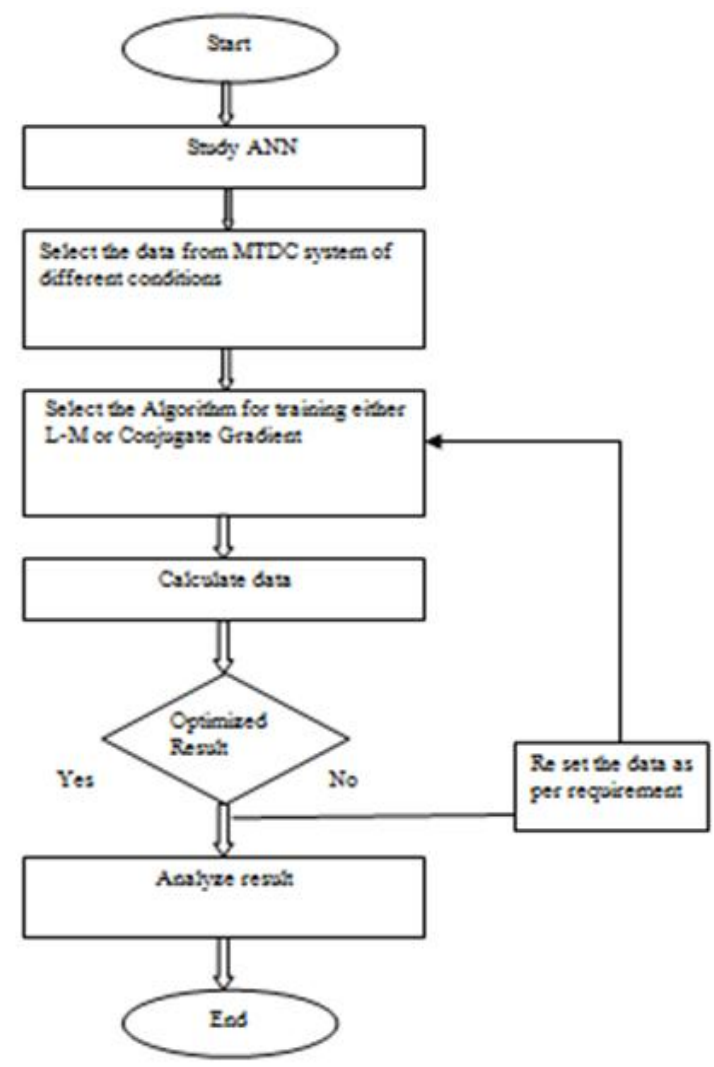

Figure no 1.3 solution Domain Algorithm

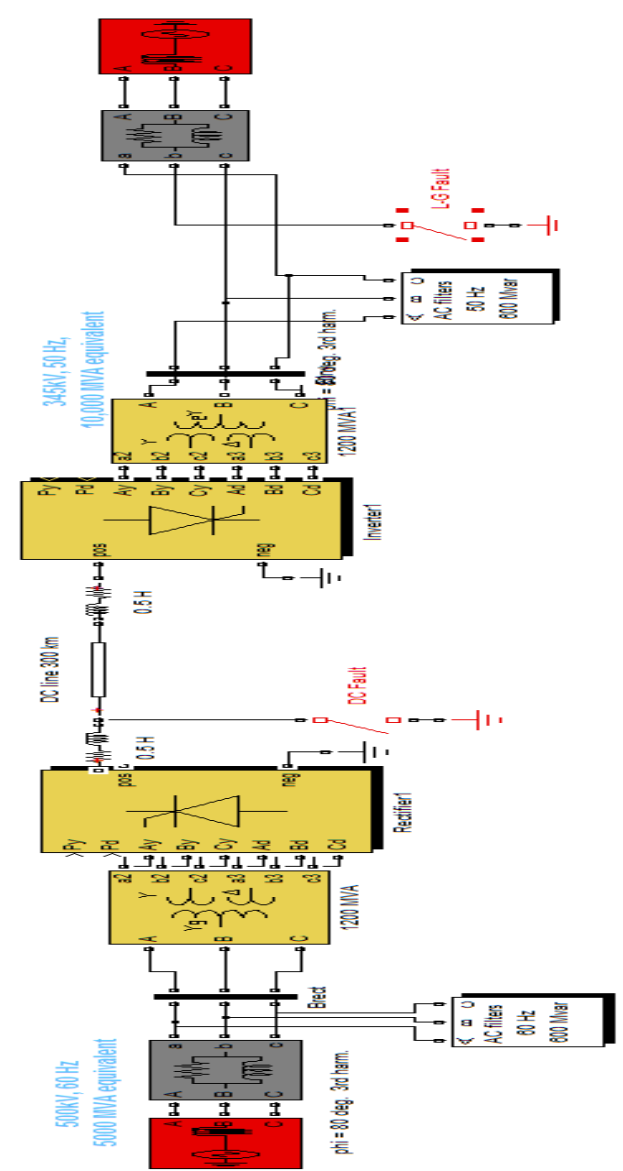

Figure 1.4 HVDC model in Simulink 
The HVDC system for the transfer of electricity is chooses because of ease of frequency matching and grid tie ups is flexible operative schedules as per the requirements. The proposed work is divided in two parts; first part is for creating the HVDC system in Simulink.

The HVDC model is choses from basic model given in demo system of Simulink. This HVDC model is tie up with different grids of different power rating and frequencies. The second step is toward condition monitoring of same system under different condition using ANN. The input and training data for ANN is generated from the Simulink model and feed it into ANN input.

Figure 1.5 shows the fault current waveform under normal operating condition:

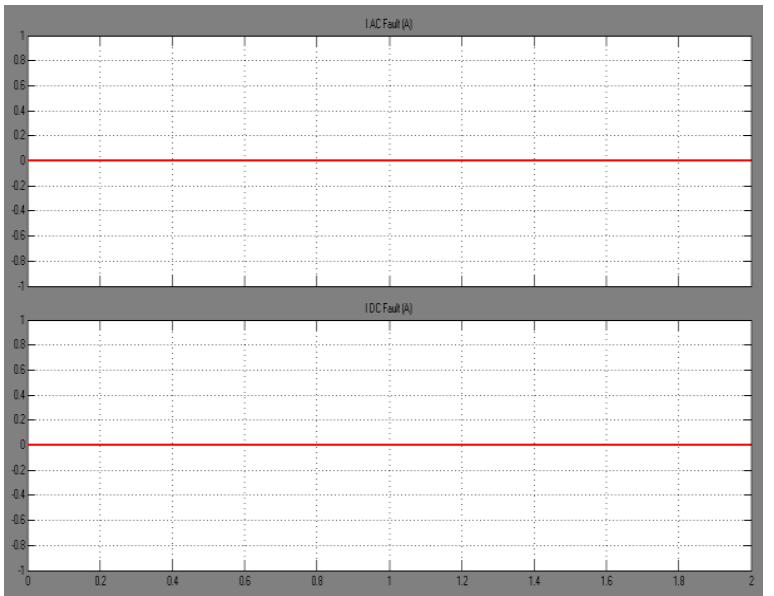

Figure 1.5 AC \& DC fault current wave form under normal condition

Figure 1.6 shows the waveform under only DC fault condition:

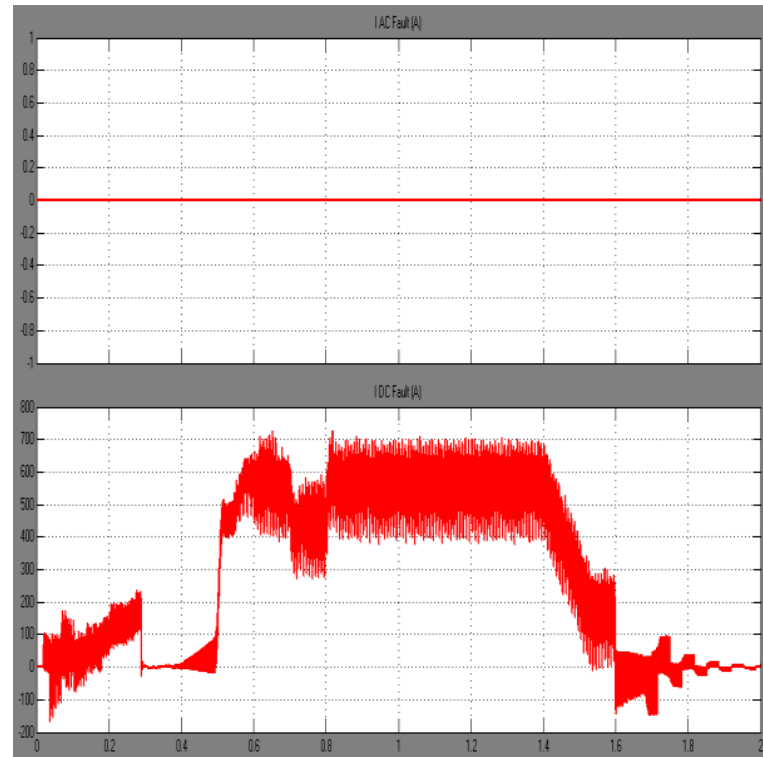

Figure 1.6 AC \& DC fault current wave form under DC fault condition
Figure 1.7 shows the waveform under only AC fault condition:

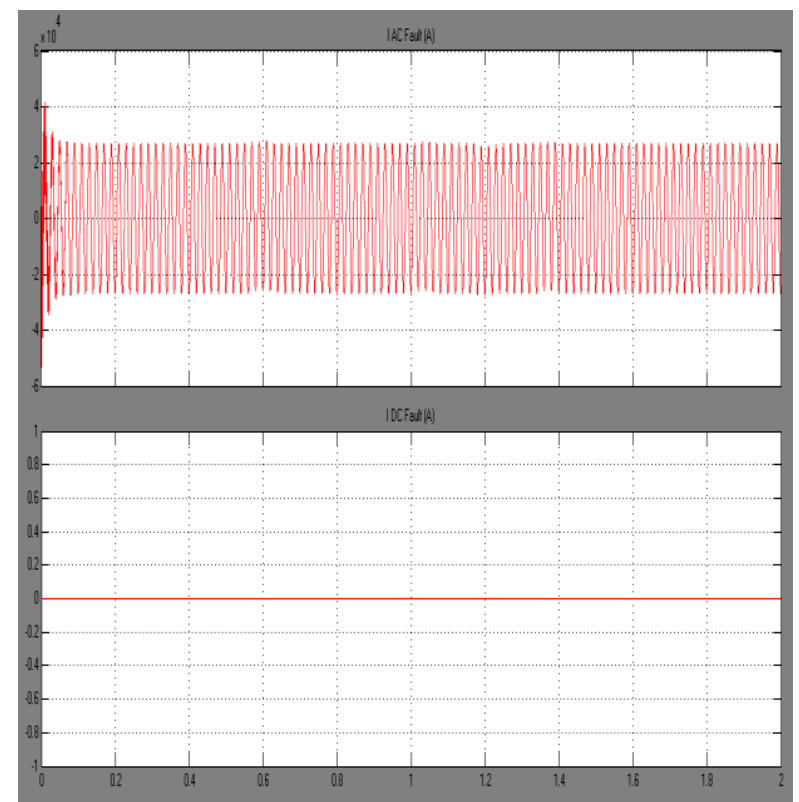

Figure 1.7 AC \& DC fault current wave form under AC fault condition

Figure 1.8 shows the waveform under both DC \& AC fault condition:

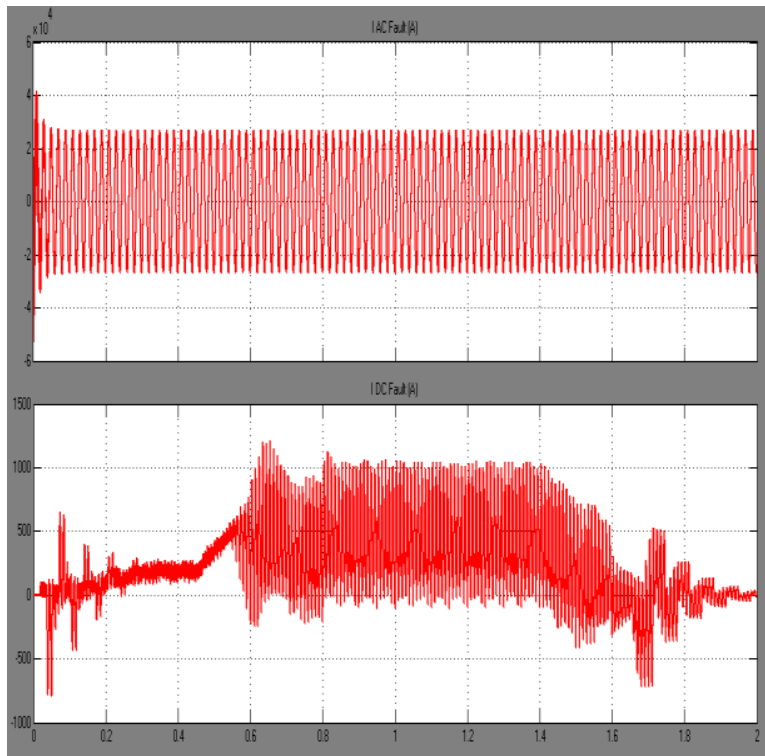

Figure 1.8 AC \& DC fault current wave form under DC \& AC fault condition

\section{FAULTS IN HVDC SYSTEM AND DETECTION USING ANN}

Mat lab is selected for applying ANN in HVDC system for fault detection. Here back propagation type neural network is chooses for the fault detection. This type of ANN is a supervised learning for which the data received from the simulation of HVDC model is used to feed as input. The 
ANN using fitting tool is chooses for fault detection and a The fitting tool uses Levenberg-Marquardt algorithm for network is created of six input layer, 25 hidden layer and training the system. This algorithm is fast in nature gives two output layers. Figure 1.8 shows the fitting neural the result in less time. Figure 1.10 shows its training network: details

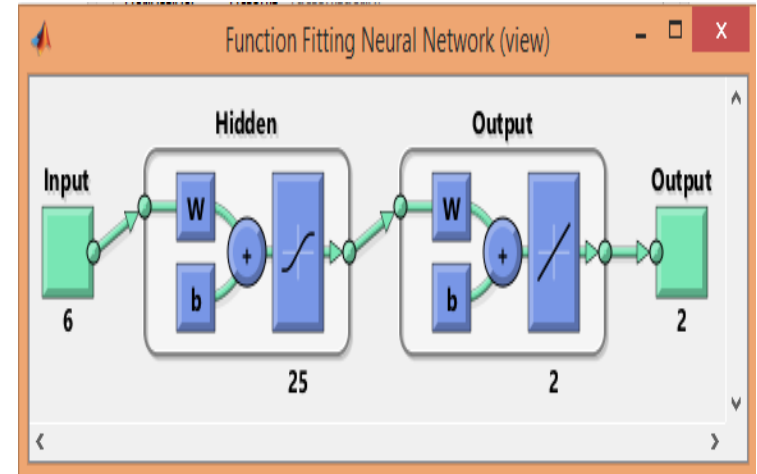

Figure 1.8 Neural Network architecture for fitting tool

Figure 1.9 shows the pattern recognition network

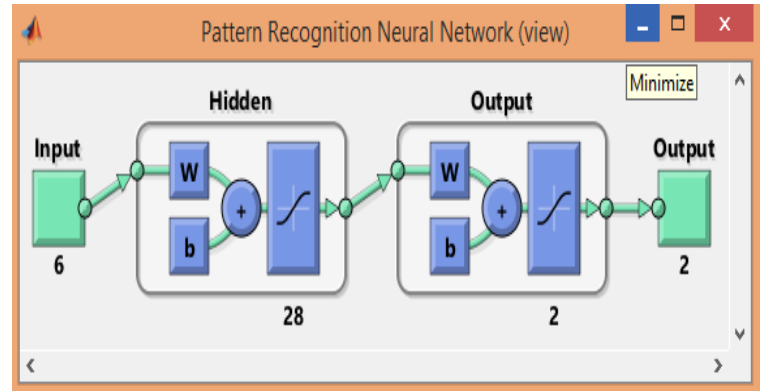

Figure 1.9 Neural Network architecture for pattern reorganization fitting tool

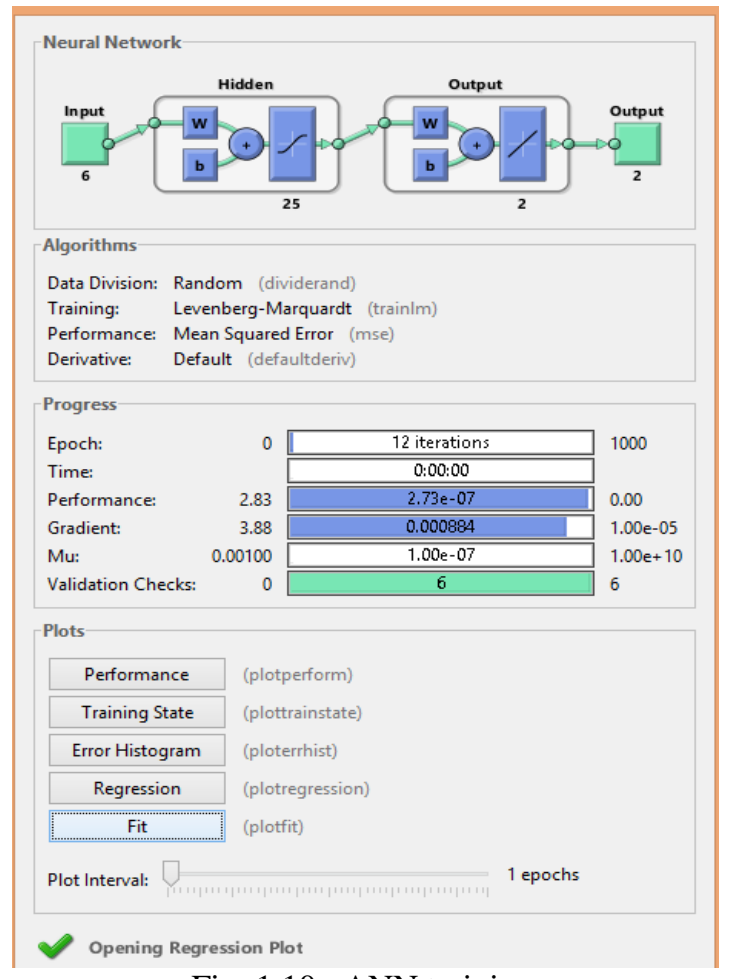

Fig. 1.10 ANN training
Figure 1.11 shows the regression curve

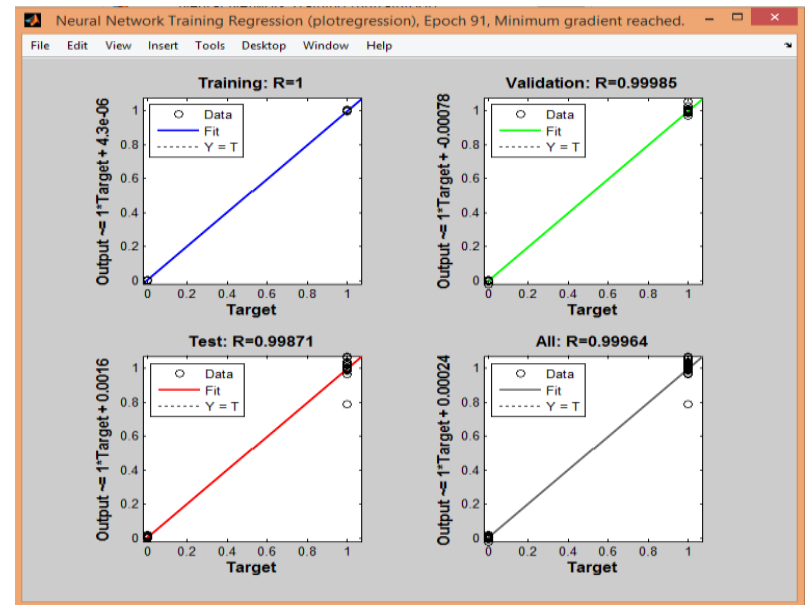

Fig. 1.11 ANN Regression curve

The comparative results show the actual condition of fault values either 0 or 1 and artificial neural network detection in every condition. Here we chooses eight samples for each type of fault to locate here while during training and input feeding we select 50 samples of each conditions

Table 1.1 Comparative Result of DC Fault

\begin{tabular}{|c|c|c|c|c|c|}
\hline $\begin{array}{c}\text { Sample } \\
\text { no }\end{array}$ & $\begin{array}{c}\text { DC } \\
\text { Fault }\end{array}$ & $\begin{array}{c}\text { BP ANN } \\
\text { using } \\
\text { Fitting } \\
\text { Tool } \\
\text { detection }\end{array}$ & $\begin{array}{c}\text { Error in } \\
\%\end{array}$ & $\begin{array}{c}\text { BP ANN } \\
\text { using } \\
\text { Pattern } \\
\text { Tool } \\
\text { detection }\end{array}$ & $\begin{array}{c}\text { Error in } \\
\%\end{array}$ \\
\hline 1 & 0 & 0.01712 & -0.01712 & 0.00013 & -0.00013 \\
\hline 2 & 0 & 0.00474 & -0.00474 & 0.00012 & -0.00012 \\
\hline 3 & 0 & 0.00696 & -0.00696 & 0.00011 & -0.00011 \\
\hline 4 & 0 & 0.00914 & -0.00914 & 0.00011 & -0.00011 \\
\hline 5 & 1 & 0.91702 & 0.08298 & 0.99971 & 0.00029 \\
\hline 6 & 1 & 0.93306 & 0.06694 & 0.99971 & 0.00029 \\
\hline 7 & 1 & 0.94306 & 0.05694 & 0.99972 & 0.00028 \\
\hline 8 & 1 & 0.95809 & 0.04191 & 0.99972 & 0.00028 \\
\hline
\end{tabular}

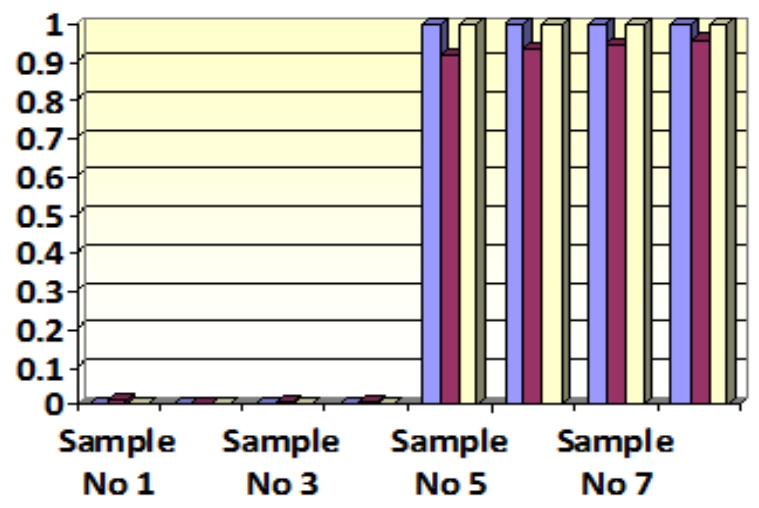

Fig. 1.12 Comparative chart of DC Fault 
Table 1.2 Comparative Result of AC Fault

\begin{tabular}{|c|c|c|c|c|c|}
\hline $\begin{array}{c}\text { Sample } \\
\text { no }\end{array}$ & $\begin{array}{c}\text { AC } \\
\text { Fault }\end{array}$ & $\begin{array}{c}\text { BP ANN } \\
\text { using } \\
\text { Fitting } \\
\text { Tool } \\
\text { detection }\end{array}$ & $\begin{array}{c}\text { Error in } \\
\%\end{array}$ & $\begin{array}{c}\text { BP ANN } \\
\text { using } \\
\text { Pattern } \\
\text { Tool } \\
\text { detection }\end{array}$ & $\begin{array}{c}\text { Error in } \\
\%\end{array}$ \\
\hline 1 & 0 & $\mathbf{0 . 0 0 3 4 6}$ & -0.00034 & 0.00098 & -0.00098 \\
\hline 2 & 0 & $\mathbf{0 . 0 0 5 8 1}$ & -0.00581 & 0.00058 & -0.00058 \\
\hline 3 & 0 & $\mathbf{0 . 0 0 8 4 1}$ & -0.00841 & 0.00042 & -0.00042 \\
\hline 4 & 0 & $\mathbf{0 . 0 0 9 1 8}$ & -0.00918 & 0.00034 & -0.00034 \\
\hline 5 & 1 & $\mathbf{0 . 9 9 8 0 4}$ & 0.00196 & 0.99873 & 0.00127 \\
\hline 6 & 1 & $\mathbf{1 . 0 9 8 8 2}$ & -0.09882 & 0.9987 & 0.0013 \\
\hline 7 & 1 & $\mathbf{0 . 9 9 5 1 3}$ & 0.088484 & 0.99973 & 0.00027 \\
\hline 8 & 1 & $\mathbf{1 . 2 2 7 5 7}$ & -0.22757 & 0.99845 & 0.00155 \\
\hline
\end{tabular}

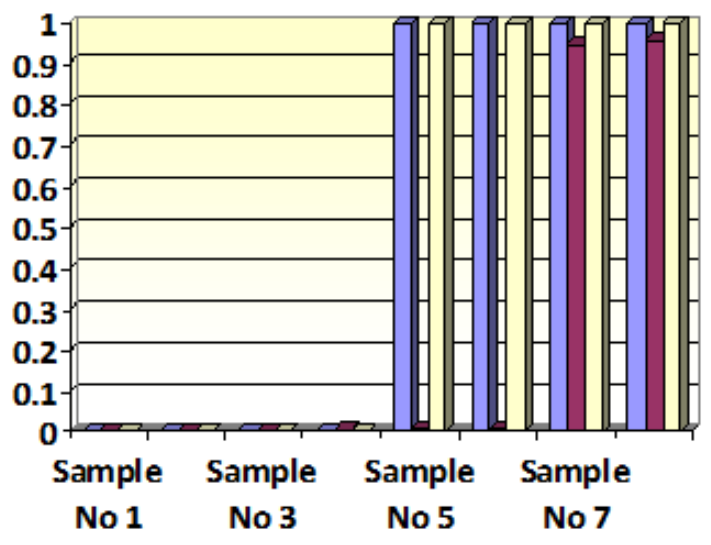

Fig. 1.13 Comparative chart of AC Fault

Table 1.3 Comparative Result of DC \& AC Fault

\begin{tabular}{|c|c|c|l|l|c|c|c|c|c|c|}
\hline $\begin{array}{c}\text { Samp. } \\
\text { no }\end{array}$ & $\begin{array}{c}\text { DC } \\
\text { Fault }\end{array}$ & $\begin{array}{c}\text { AC } \\
\text { Fault }\end{array}$ & $\begin{array}{l}\text { BP ANN using } \\
\text { Fitting Tool } \\
\text { detection }\end{array}$ & \multicolumn{3}{|c|}{ Error in \% } & \multicolumn{2}{|c|}{$\begin{array}{l}\text { BP ANN using } \\
\text { Pattern } \\
\text { Tool detection }\end{array}$} & \multicolumn{2}{c|}{ Error in \% } \\
\hline & & & AC & DC & AC & DC & AC & DC & AC & DC \\
\hline 1 & 1 & 1 & 1.003 & 0.96541 & -0.003 & 0.03459 & 0.99999 & 0.99994 & 0.00001 & 0.00001 \\
\hline 2 & 1 & 1 & 0.98708 & 0.99339 & 0.01292 & 0.00661 & 0.99996 & 0.99999 & 0.00001 & 0.00001 \\
\hline 3 & 1 & 1 & 1.00316 & 0.96258 & -0.00316 & 0.03742 & 0.99999 & 0.99993 & 0.00001 & 0.00001 \\
\hline 4 & 1 & 1 & 0.98860 & 0.99341 & 0.0114 & 0.00659 & 0.99996 & 0.99999 & 0.00001 & 0.00001 \\
\hline 5 & 1 & 1 & 1.00347 & 0.96007 & -0.00347 & 0.038993 & 0.99989 & 0.99992 & 0.00001 & 0.00001 \\
\hline 6 & 1 & 1 & 0.99044 & 0.99164 & 0.00956 & 0.00836 & 0.99994 & 0.99999 & 0.00001 & 0.00001 \\
\hline 7 & 1 & 1 & 1.00383 & 0.95660 & -0.00383 & 0.0434 & 0.99988 & 0.99991 & 0.00001 & 0.00001 \\
\hline 8 & 1 & 1 & 0.99240 & 0.99145 & 0.0076 & 0.00855 & 0.99992 & 0.99999 & 0.00001 & 0.00001 \\
\hline
\end{tabular}

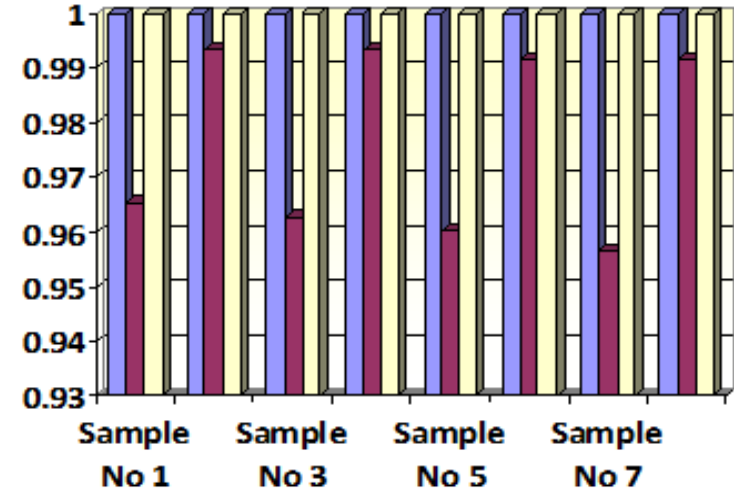

Fig. 1.14Comparative chart of DC \& AC Fault

\section{CONCLUSION}

The paper tries here to present the fult classification and detection for HVDC system using ANN. The HVDC model is presented here for the condition monitoring of overall system either it is AC or DC and artificial neural network is a modern technique which is capable to give fast and accurate results; the need of present time so the selected algorithm gives batter result for condition monitoring of HVDC system. Following conclusion are drawn from the presented work:
1. Two different grids are selected for the tie up of HVDC transmission system.

2. The grid configuration for first grid is 5000MVA, $500 \mathrm{KV}, 60 \mathrm{~Hz}$

3 . The grid configuration for second grid is $10000 \mathrm{MVA}$, $345 \mathrm{KV}, 50 \mathrm{~Hz}$

4. There are four conditions are choses here for HVDC system simulation healthy system, DC fault, AC fault, AC \& DC both type of fault.

5. For each type of fault 50 samples are used for training and testing ANN.

6. For validation there are 8 samples are selected for each case

7. In each case no fault and faulty conditions both were validated through ANN techniques using pattern recognition and fitting tool

8. In both training algorithms results gave error less than $1 \%$

Fitting tool is very fast in computation while pattern recognition is more accurate in result but its speed is comparatively slow and require more iterations

\section{REFERENCES}

[1] V. sulochana, A. Francis, Dr. Andrew Tickle, "Morphology Based Radon Processed Neural network for Transmission Line Fault Detection", International Conference on Advances in Computing, 
Communications and Informatics (ICACCI)IEEE, pp. 1137-1143, 2015.

[2] Y.M. Yeap, A. UKIL, "Wavelet Based Fault Analysis in HVDC System"Annual Conference of the IEEE Industrial Electronics SocietyIEEE, pp. 2472-2478, 2014.

[3] M. Jamil, S. Kumar Sharma \& R. Singh, "Fault detection and classification in electrical power transmission system using artificial neural network"SpringerPlus, pp. 1-13, 2015.

[4] I. Baqui, I. Zamora, J. Mazon, G. Buigues, "High impedance fault detection methodology using wavelet transform and artificial neural networks"Elsevier, pp. 1325-1333, 2011.

[5]M Ramesh,A. Jaya Laxmi, "Fault Identification in HVDC using Artificial Intelligence - Recent Trends and Perspective" IEEE, pp. $1-6,2012$.

[6] K. G. Narendra, V. K. Sood, K. Khorasani, R. Patel, “Application of a Radial Basis Function (RBF) Neural Network for Fault Diagnosis in a HVDC System" IEEE, pp. 177-183, 1998.

[7] J. Moshtagh, M. Jannati, H. R. Baghaee and E. Nasr, "A Novel Approach for Online Fault Detection in HVDC Converters" IEEE, pp. 307-311, 2008.

[8] L LLai, F Ndeh-Che, Tejedo Chari, "Fault Identification In HVDC Systems With Neural Networks", IEE 2nd International Conference on Advances in Power System Control, Operation and Management, December 1993, Hang Kong, pp. 231-236.

[9] M.Khodaparastan, ,A.S.Mobarake, G.B.Gharehpetian, S.H Fathi, "Smart Fault Classification in HVDC System Based on Optimal Probabilistic Neural Networks", pp. 1-4

[10] H. Kanoh, K. Kanemaru, M. Kaneta, M. Nishiura, "A Study on Practical Fault Location System for Power Transmission Lines using Neural Networks",pp. 9-13.

[11] H. Etemadi, V.K. Sood, K. Khorasani, R. V. Patel, "Neural Network Based Fault Diagnosis in an HVDC System", International Conference on Electric Utility Deregulation and Restructuring and Power Technologies, 2000, pp. 206-214.

[12] Hang Cui, NiannianTu, "HVDC Transmission Line Fault Localization Base on RBF Neural Network with Wavelet Packet Decomposition", IEEE International Conference onService Systems and Service Management (ICSSSM), 2015, pp. 1-4.

[13] K.S.SuaruP, H.S.Chandrasekharalah, "Fault detection and Diagnosis of Power Converters using Artificial Neural Network", IEEE International Conference on Power Electronics, Drives and Energy Systems for Industrial Growth, 1996, pp. 1054-1058.

[14] P.Sanjeevikumar, B. Paily, M. Basu, M. Conlon, "Classification of Fault Analysis of HVDC Systems using Artificial Neural Network", IEEE Power Engineering Conference (UPEC), 2014, pp. 1-5.

[15] Preeti Gupta, R. N. Mahanty, "Artificial Neural Network based Fault Classifier and Locator for Transmission Line Protection", IOSRJEEE, Vol. 11, Issue 1 Ver. I (Jan - Feb. 2016), PP 41-53.

[16] S. A. M. Javadian, M.-R.Haghifam, N. Rezaei, "A Fault Location and Protection Scheme for Distribution Systems in presence of DG Using MLP Neural Networks", Power \& Energy Society General Meeting, 2009, IEEE, pp. 1-8.

[17] S.A.M. Javadian, A.M. Nasrabadi, M.R. Haghifam, J. Rezvantalab, "Determining Fault's Type and Accurate Location in Distribution Systems with DG Using MLP Neural Networks", IEEE International Conference on Clean Electrical Power, 2009 pp. 284289.

[18]Xiangning Lin, Peng Mao, HanliWeng, Bin Wang, Z Q Bo and A Klimek, "Study on Fault Location for High Voltage Overhead Transmission Lines Based on Neural Network System", IEEE, International Conference on Intelligent Systems Applications to Power Systems, 2007, pp. 1-5

[19] D.S. Gastaldello, A.N. Souza, C.C.O. Ramos, P. da Costa Junior and M.G. Zago, "Fault Location in Underground Systems Using Artificial Neural Networks and PSCAD/EMTDC", IEEE 16th International Conference on Intelligent Engineering Systems, June 13-15, 2012, pp. 423-427.

[20] F. Dehghani, H. Nezami, "A New Fault Location Technique on Radial Distribution Systems Using Artificial Neural Network", 22nd International Conference on Electricity Distribution, CIRED2013, pp. 1-4.

[21] P. Bunnoon, "Fault Detection Approaches to Power System: Stateof-the-Art Article Reviews for Searching a New Approach in the
Future", International Journal of Electrical and Computer Engineering (IJECE) Vol. 3, No. 4, August 2013, pp. 553 560.

[22]Kaiping Yu, Fang Yang, Hong Guo, JinquanXu, "Fault Diagnosis and Location of Brushless DC Motor System Based on Wavelet Transform and Artificial Neural Network", International Conference on, Electrical Machines and Systems (ICEMS), 2010, pp. 1-5.

[23] H. Khorashadi-Zadeh, M. R. Aghaebrahimi, "A Novel Approach to Fault Classification and Fault Location for Medium Voltage Cables Based on Artificial Neural Network", World Academy of Science, Engineering and Technology,2008, pp. 1100-1103.

[24] Mr. Shrishail H. Patale, Prof. M. S. Potdar, "A Review on HVDC Transmission Line Protection with Different Techniques"International Journal of Engineering Sciences \& Research Technology, ISSN: 2277-9655, pp. 820-824.

[25] L. L. Lal, F Wdeh-Che, TejedoChari, "HVDC Systems Fault Diagnosis with Neural Networks", 1993 The European Power Electronics Association, pp. 145-150.

[26] H. Livani, C. Y. Evrenosoglu, "A single-ended fault location method for segmented HVDC transmission line", 2013 Elsevier, Electric Power Systems Research 107 (2014) 190- 198.

[27] N. P. Srivastava, R. K. Srivastava, P. K. Vashishtha, "Fault Detection and Isolation (FDI) Via Neural Networks", ISSN : 22489622, Vol. 4, Issue 1( Ver.1), January 2014, pp.81-86.

[28] S. LeBlond, R.BerthoJr., D.V.Coury, J.C.M.Vieira, "Design of protection schemes for multi-terminal HVDC systems" Elsevier 2015, pp. 966-973.

[29] Zhiqing Yao, Qun Zhang, Peng Chen, Qian Zhao, "Research on fault diagnosis for MMC-HVDC Systems", Springer, pp. 1-7.

[30] A. Abu-Jasser, M. Ashour, "A BackpropagationFeedforward NN for Fault Detection and Classifying of Overhead Bipolar HVDC TL Using DC Measurements", Journal of Engineering Research and Technology, Vol. 2, Issue 3, September 2015, pp. 197-202.

[31] S. Tom, J. Thomas, Ganesh M, "A Novel Algorithm for Fault Location and Identification in HVDC Transmission Lines Based on Transients", IEEE International Conference on Emerging Research in Electronics, Computer Science and Technology - 2015, pp. 224229.

[32] C. Venkatesh, P. VenugopalRao, "Wavelet-ANN based Classification of HVDC Converter Faults", International Conference on Power Systems (ICPS), 2016 IEEE, pp. 1-5.

[33] M. S. Shastrakar, M. B. Gaikwad, "Application of Artificial Neural Network In Fault Detection of HVDC Converter", International Journal of Engineering Research \& Technology (IJERT) Vol. 2 Issue 5, May - 2013 ISSN: 2278-0181.

[34] A. Swetha, P. Krishna Murthy, N. Sujatha and Y. Kiran, "A Novel Technique for the Location of Fault on A HVDC Transmission Line", ARPN Journal of Engineering and Applied Sciences VOL. 6, NO.11, NOV. 2011 ISSN 1819-6608, pp. 62-67.

[35] S. N. Sivanandam, S. Sumathi, S. N. Deepa, "Introduction to Neural Networks using MATLAB 6.0.", The McGraw- Hill Companies.

[36] Sherin Tom, Jaimol Thomas, "A New Fault Identification Method for HVDC Transmission Line", International Journal of Science and Research (IJSR) Volume 4 Issue 11, November 2015, ISSN (Online): 2319-7064, pp. 729-734.

[37] S. M. Mangalge, S. D. Jawale, "A Review on Fault Location Techniques in Long HVDC Transmission Lines", International Journal of Advanced Research in Electrical,Electronics and Instrumentation Engineering, Vol. 5, Issue 5, May 2016, pp. 42204226.

[38] Pannala Krishna Murthy, J.Amarnath, S. Kamakshiah, B.P. Singh, "Wavelet Transform Approach for Detection and Location of Faults in HVDC System", Third international Conference on Industrial and Information Systems, 2008. ICIIS 2008, IEEE, pp. 1-6.

[39] L. wen-li, S. li-qun, "The Review of High Voltage DC Transmission Lines Fault Location", International Journal of Computer, Consumer and Control (IJ3C), Vol. 3, No.4 (2014), pp. 21-28. 